\title{
Melanization of Bomirski hamster amelanotic melanoma cells (Ab line) depends on the type of culture medium
}

\author{
Aneta Skoniecka $^{1}$, Agata Zauszkiewicz-Pawlak ${ }^{2}$, Agata Tyminska' ${ }^{1}$, Miroslawa Cichorek ${ }^{1}$ \\ ${ }^{1}$ Department of Embryology, Medical University of Gdansk, Poland \\ ${ }^{2}$ Department of Histology, Medical University of Gdansk, Poland
}

\begin{abstract}
Introduction. The effect of melanogenesis intensity on melanoma biology remains an open question, and the biological differences between melanotic and amelanotic melanoma cells have not yet been satisfactorily documented. As a result, the melanization of melanoma cells in in vitro cultures is not considered among experimental procedures. The aim of this study was to investigate the effect of the medium used to culture Bomirski amelanotic $\mathrm{Ab}$ melanoma cells on the melanogenesis process.

Material and methods. Amelanotic melanoma cells $(\mathrm{Ab})$ were cultured in two media recommended for in vitro melanoma cell cultures, RPMI and DMEM. The melanization was evaluated by determining the melanin and tyrosinase presence in the cells using spectrophotometrical and western blot methods, respectively. Changes in Ab melanoma cells' ultrastructure were determined using electron microscopy (EM).

Results. The medium with higher level of tyrosine (DMEM) induced significant melanization of amelanotic melanoma cells $(\mathrm{Ab})$ after only $24 \mathrm{~h}$, while the RPMI medium, with a lower level of tyrosine, weakly affected melanin production. Melanization of Ab cells was paralleled by an increase in the amount of tyrosinase protein. Induced melanization was easily observed on EM-micrographs in the form of newly formed melanosomes containing melanin pigment. Melanosomes at stages from one (I) to four (IV) were observed.

Conclusions. Culture medium has an important effect on the in vitro biology of amelanotic melanoma cells, since it can affect the rate of cellular melanization. The appropriate medium should be carefully selected, taking into account the known biology of the melanoma cells being used. (Folia Histochemica et Cytobiologica 2018, Vol. 56, No. 4, 207-214)
\end{abstract}

Key words: Bomirski melanoma; amelanotic melanoma; melanogenesis; culture media; melanin; tyrosinase; western blotting; electron microscopy

\section{Introduction}

Melanoma cells are characterized by different amounts of melanin, and the color of a melanoma tumor can range from black through brown and blue, to white $[1,2]$. Melanomas lacking or with very low levels of melanin are referred to as amelanotic, and can be difficult to identify $[3,4]$. Amelanotic melanomas occur in $2-12 \%$ of all skin melanoma patients

\footnotetext{
Correspondence address:

M. Cichorek, Ph.D.

Department of Embryology, Medical University of Gdansk

Debinki 1 St, 80-210 Gdansk, Poland

e-mail: miroslawa.cichorek@gumed.edu.pl
}

$[2,3,5]$. Additionally, it is estimated that from $14 \%$ to $60 \%$ of melanoma metastases are amelanotic, even when the primary melanoma is melanotic [6,7], and the amelanotic form also dominates among melanomas in children [8]. Amelanotic melanoma cells are thus not so rare in general. The question of the effect of melanogenesis on the biology of melanoma cells remain controversial, mainly because there have been insufficient systemic studies of the comparative biology of melanotic and amelanotic melanoma cells. Melanotic and amelanotic melanoma forms thus receive the same treatment, despite suggestions that melanoma cells with melanin differ from those without melanogenesis [9-13]. In our laboratory, we use 
the Bomirski hamster melanoma model to compare the biology of melanotic and amelanotic melanomas; this consists of two basic lines, melanotic $\mathrm{Ma}$ and amelanotic $\mathrm{Ab}$, which arose as a consequence of spontaneous alteration from the Ma form. The change of a melanotic into an amelanotic melanoma results in growth rate acceleration, a lack of melanosomes, ultrastructural changes in cells [14], and a low rate of spontaneous apoptosis, as well as high susceptibility to induced apoptosis [15-18]. The amelanization of melanoma cells is not well understood. It has been proposed that the lack of melanin in these cells is the result of disturbances in the biosynthesis of premelanosomes $[14,19]$. The Ab line is a fast-growing, highly anaplastic, metastasizing malignant tumor. Słomiński et al. observed that $\mathrm{Ab}$ cells in vitro short cultures regained the ability to synthesize melanin [20,21].

We have observed that the media recommended for in vitro cultivation of melanoma cells, RPMI1640 and DMEM, induce the melanization of the amelanotic $\mathrm{Ab}$ line to different degrees. Tyrosinase (TYR) plays an essential role in the process of melanogenesis, carrying out tyrosine hydroxylation to L-3,4-dihydroxyphenylalanine (DOPA), which is rapidly oxidized to dopaquinone [22]. Brown-black eumelanin is produced by spontaneous cyclization of dopaquinone to dopachrome which, in the presence of the enzymes tyrosinase-related protein 1 (TRP1) and tyrosinase-related protein 2 (TRP2), can change into DHICA-melanin (DHI-2-carboxylic acid) or insoluble DHI-melanin (5,6-dihydroxyindole) [22]. Taking this into account, we wished to compare the rate of melanization of amelanotic Ab melanoma cells during culturing of up to $48 \mathrm{~h}$ in DMEM and RPMI media by determining tyrosinase protein and melanin levels with the cell ultrastructural changes.

\section{Material and methods}

Bomirski hamster melanoma model. The Bomirski hamster melanoma model has two basic melanoma lines: the melanotic $\mathrm{Ma}$ and the amelanotic $\mathrm{Ab}$. The native melanotic $\mathrm{Ma}$ line was derived from a spontaneous melanoma of the skin (near the nose) in a male Syrian (golden) hamster in 1959; it has been maintained by serial transplantation through random-bred animals [12]. The amelanotic melanoma line (Ab) originated in 1963 from the Ma form by a spontaneous alteration [14]. The $\mathrm{Ab}$ amelanotic melanoma lost the ability to produce melanin as the result of disturbances in melanosome formation, but retains the tyrosinase activity at a much lower level than Ma line [14, 20]. The lack of melanin synthesis is accompanied by changes in many biological features, such as faster tumor growth rate, shorter animal survival, and changes in cells' ultrastructure [12].
The amelanotic melanoma was transplanted on 3-12 month-old male Syrian (golden) Mesocricetus auratus Waterhouse hamsters. The experimental procedures were approved by the Animal Ethics Committee at the Medical University of Gdansk (4/2011) and conducted in accordance with National Health and Medical Research Council's guide for the care and use of laboratory animals.

Isolation of melanoma cells. Both types of melanoma cells were isolated from the solid tumors by a nonenzymatic method reported previously [16]. The cell suspension contained 90-95\% viable cells, as estimated by trypan blue dye exclusion assay. The primary cells were cultured at a density of $2.5 \times 10^{6}$ in $10 \mathrm{ml}$ of basic medium (RPMI, Biomed-Lublin, Poland), supplemented with $10 \%$ FBS (fetal bovine serum, Sigma-Aldrich, St. Louis, MO, USA) and antibiotics (100 units/ml penicillin, $100 \mu \mathrm{g} / \mathrm{ml}$ streptomycin, Sigma-Aldrich) on Petri dishes. After isolation, the cells were precultured in the basic medium at $37^{\circ} \mathrm{C}$, at $5 \%$ of $\mathrm{CO}_{2}$ for $20 \mathrm{~h}$ before experiments.

Cell culture. There were two experimental groups of cell culture: the first was cultured in the basic RPMI-1640 (Roswell Park Memorial Institute) medium, and the second in DMEM (Dulbecco Modified Minimal Essential Medium), both supplemented with $10 \%$ FBS and antibiotics. DMEM has more $(72 \mathrm{mg} / \mathrm{l}) \mathrm{L}$-tyrosine, the primary amino acid for the melanin synthesis, than RPMI $(20 \mathrm{mg} / \mathrm{l})$. The media differ also in their level of phenylalanine $(66 \mathrm{mg} / \mathrm{l}$ in DMEM, $15 \mathrm{mg} / \mathrm{l}$ in RPMI), which is hydroxylated into L-tyrosine in the presence of L-phenylalanine hydroxylase. Both media are recommended for culturing melanoma cells in vitro. The melanization of Ab melanoma cells was determined by the cell ultrastructure, melanin content, and tyrosinase protein level after 24 and $48 \mathrm{~h}$ incubation in the media. Ma melanoma cells cultured for $24 \mathrm{~h}$ in RPMI were used as a positive control for the melanin content and tyrosinase protein level.

Ultrastructural changes. The collected cells were rinsed in PBS and the pellet immediately fixed in a solution of $2.5 \%$ glutaraldehyde (GA) in Na-cacodylate buffer at $\mathrm{pH} 7.4$. Fixation was carried out at $4^{\circ} \mathrm{C}$ for $24 \mathrm{~h}$, and the material was then rinsed three times in the same buffer. Postfixation was performed with $1 \%$ osmium tetroxide in an Na-cacodylate buffer for $2 \mathrm{~h}$. Following fixation, the cells were dehydrated in a graded series of ethanol, immersed in propylene oxide, embedded in Epon 812 , and polymerized at $37^{\circ} \mathrm{C}$. Sectioning was performed with a glass knife on an OmU2 ultramicrotome (Richert, Austria). Semithin sections $(1.5 \mu \mathrm{m})$ were stained with toluidine blue and examined under a light microscope (Jenaval, Carl Zeiss Jena, Germany). Ultrathin sections were placed on formvar-covered copper grids and double stained with uranyl acetate and lead citrate. Observations were made using a 1200 EXII transmission electron microscope (Jeol, Tokyo, Japan) at an accelerating voltage of $80 \mathrm{kV}$. 
Melanin content. The total amount of melanin in cells was estimated spectrophotometrically (Multiscan FC, Thermo Scientific). $2 \times 10^{6}$ cells were incubated with $1 \mathrm{~N} \mathrm{NaOH}$ in $10 \% \mathrm{DMSO}$ for $2 \mathrm{~h}$ at $60^{\circ} \mathrm{C}$ with shaking [23]. Samples were plated on 96-well plates and the absorbance was measured at $450 \mathrm{~nm}$. Melanin content was determined using the standard curve of synthetic melanin (Sigma-Aldrich).

Immunoblotting of tyrosinase. Total cell lysates were obtained by incubating $2 \times 10^{6}$ cells in the lysis buffer RIPA (Sigma-Aldrich) for $1 \mathrm{~h}$ on ice, and then spinning for 15 min at 14,000 rpm. The supernatants were collected and stored at $-70^{\circ} \mathrm{C}$ for further processing. The total protein was quantified using a Bradford assay (Bio-Rad, Hercules, CA, USA). $60 \mu \mathrm{g}$ of lysate was subjected to electrophoresis in $10 \%$ SDS gel under reducing conditions and transferred to nitrocellulose membrane (Bio-Rad). After $1 \mathrm{~h}$ blocking in $5 \%$ nonfat milk, membranes were probed overnight with rabbit polyclonal antityrosinase antibody (1:5000, Abcam) at $4^{\circ} \mathrm{C}$. After washing, horseradish peroxide (HRP)-conjugated anti-rabbit IgG was added for $1 \mathrm{~h}$ (1:10000, Sigma-Aldrich). The blots were reprobed with an antibody against $\beta$-actin (1:6000, Sigma-Aldrich) to confirm that there were equal amounts of protein in the lanes. A chemiluminescent signal was developed using the Super Signal West Pico system (Thermo Scientific, USA) and documented by a Chemi Doc XRS+System camera (BioRad). Band intensity was semiquantified using ImageLab 5.2.1 software (National Institutes of Health, USA) and was shown as a ratio to actin.

Statistical analysis. Statistical analysis was performed using the Statistica data analysis software system version 12 (Statsoft, Krakow, Poland). Data are displayed as arithmetical mean \pm standard deviation (SD). The nonparametric Jonckheere and U Mann Whitney tests were used; differences with $\mathrm{p}<0.05$ were considered statistically significant.

\section{RESULTS}

\section{Melanin content}

At the beginning of experiment $(0 \mathrm{~h}$, after overnight preincubation), the Ab melanoma cells had a low level of melanin $(131 \mu \mathrm{g} / \mathrm{ml})$ as the result of these cells' transfer from in vivo to in vitro growth conditions. The rate of melanization depends on the medium used, being much faster in DMEM than in RPMI. The Ab cells undergo very weak melanization in the RPMI medium; after 48 hours melanin levels increased by $32 \%$ ( $p<0.05$, Fig. 1A). Melanization in RPMI during the course of the whole incubation was not easily noticed macroscopically (Fig. 1B). As a result of melanization, amelanotic $\mathrm{Ab}$ cells in DMEM changed morphology, becoming rounded and detached. Pigmentation in DMEM was macroscopically observed after $24 \mathrm{~h}$, when the melanin content increased

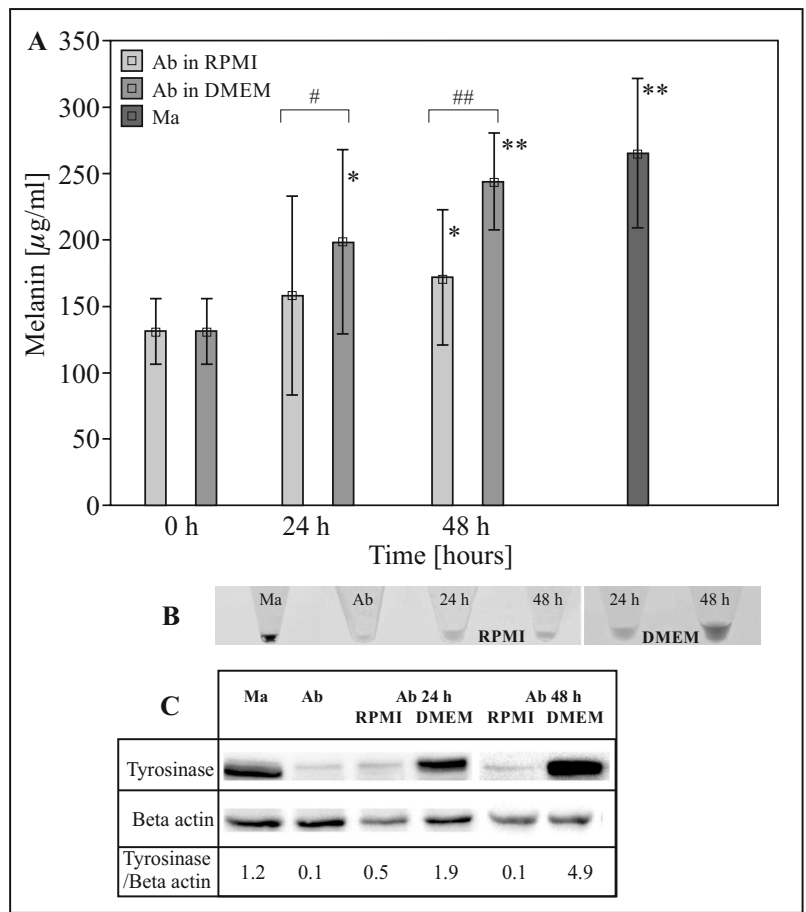

Figure 1. Parameters of Ab melanoma cell melanization during in vitro culturing for $24 \mathrm{~h}$ and $48 \mathrm{~h}$ in RPMI and DMEM. A. Comparison of melanin content of Ab amelanotic melanoma cells cultured in RPMI and DMEM media. Ma melanotic melanoma cells were used as a positive control for melanin production. Values are means \pm SDs of $5(0 \mathrm{~h})$ and 7 (24 and $48 \mathrm{~h}$ ) experiments. Statistical analysis was performed using the nonparametric Jonckheere and U Mann-Whitney tests. Statistically significant increases were observed in melanin levels in comparison to the $0 \mathrm{~h}$ time point $\left(^{*}\right)$ and between RPMI and DMEM (\#); \#, * $\mathrm{p}<0.05$; \#\#, ** $\mathrm{p}<0.01$. B. Macroscopic darkening of cell lysates from cultured cells. C. Tyrosinase protein levels in Ab melanoma cells after $24 \mathrm{~h}$ (Ab24h) and $48 \mathrm{~h}$ (Ab48h) of incubation in RPMI or DMEM, detected by western blotting. Ma melanoma cells were used as a positive control for tyrosinase presence. Beta actin was estimated as a protein loading control. The tyrosinase-to-beta-actin ratio reflects the relative changes of the tyrosinase content during culturing.

by over $50 \%$, reaching $198 \mu \mathrm{g} / \mathrm{ml}(\mathrm{p}<0.05)$. After $48 \mathrm{~h}$ melanin synthesis increased by an additional $20 \%$ $(\mathrm{p}<0.01)$ and darkening of cells was observed macroscopically (Fig. 1A, B). After two days of incubation of Ab melanoma cells in DMEM, the melanin level $(246 \mu \mathrm{g} / \mathrm{ml})$ was similar to that in the melanotic Ma melanoma (265 $\mu \mathrm{g} / \mathrm{ml})$ (Fig. 1A).

\section{Tyrosinase protein level determined by western blot}

Tyrosinase protein from the Ma melanotic and $\mathrm{Ab}$ amelanotic melanoma cells forms bands at the same position (molecular weight $68 \mathrm{kDa}$ ). In the $\mathrm{Ab}$ amelanotic melanoma, tyrosinase was detected at a very 


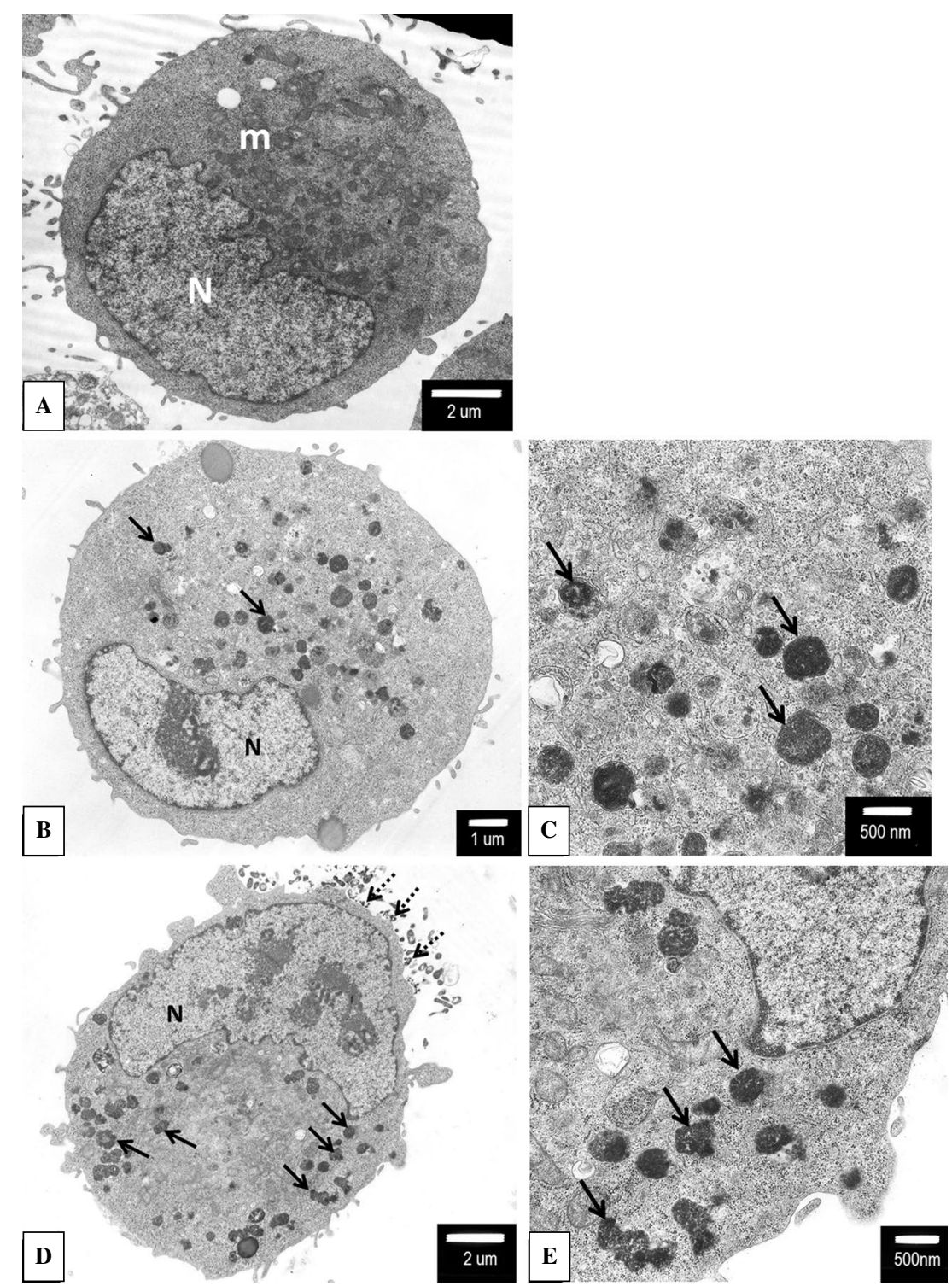

Figure 2. Ultrastructural changes in Ab amelanotic melanoma cells cultured in RPMI medium. At time 0, cells (A) showed no apparent melanosomes, had typical euchromatic nuclei $(\mathrm{N})$ and cytoplasm occupied by numerous mitochondria (m); some microvilli were seen on the outline of the cell. Cells cultured for $24 \mathrm{~h}(\mathbf{B}, \mathbf{C})$ and $48 \mathrm{~h}(\mathbf{D}, \mathbf{E})$ showed very weak melanization. Granular melanosomes (arrows) were observed in the cytoplasm. After $48 \mathrm{~h}$, melanin granules (dotted arrows) were seen outside the cell; these had plausibly been extruded from the cells (D).

low level - tenfold lower than in the Ma melanotic line. Cells cultured in RPMI showed an increase in tyrosinase level after $24 \mathrm{~h}$, but then the protein level seemed to decrease (Fig. 1C).

$\mathrm{The} \mathrm{Ab}$ amelanotic melanoma cells cultured in DMEM rapidly increased in tyrosinase content over cultivation time (Fig. 1C), and this was accompanied by the darkening of cell pellets (Fig. 1B). After the first day of culturing of $\mathrm{Ab}$ amelanotic melanoma cells their tyrosinase protein level reached a value similar to the melanotic Ma cells (Fig. 1C). After one additional day, the amount of enzyme more than doubled.

\section{Ultrastructural changes in amelanotic melanoma} cells determined by transmission electron microscopy The ultrastructure of the Bomirski Ab amelanotic hamster melanoma cells was examined with particular reference to the melanization process. Cells cultured for 24 or $48 \mathrm{~h}$ in the medium with low tyrosine content (RPMI) (Fig. 2) demonstrated weak melanization as compared with cells incubated in DMEM medium containing higher level of tyrosine (Fig. 3). The latter showed more advanced melanization with higher content of melanosomes. Although different stages of granular melanosomes development were seen, 


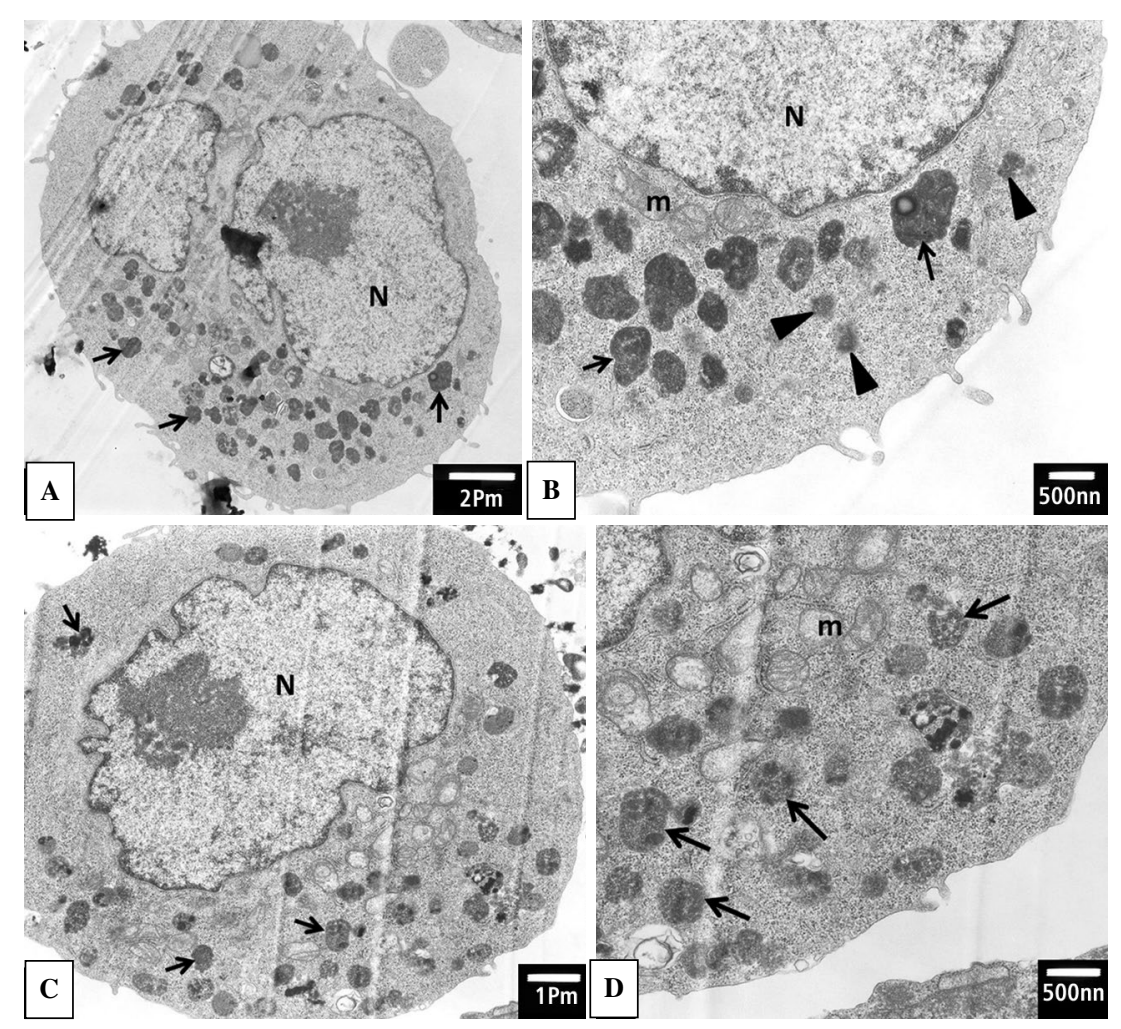

Figure 3. Induced melanization of Ab amelanotic melanoma cells incubated in DMEM for $24 \mathrm{~h}(\mathrm{~A}, \mathbf{B})$ and $48 \mathrm{~h}(\mathbf{C}, \mathbf{D})$. TEM images of cell cultures revealed an increase in the number of melanosomes with time. We observed melanosomes (arrows) as membrane-limited dense granules containing melanin, and occasionally some premelanosomes (arrowheads) with patterned matrices; $\mathrm{N}$, nucleus.

the III and IV stages melanosomes dominated in cells cultured in DMEM for $48 \mathrm{~h}$. These granular, rounded, 200-600 nm-wide melanosomes, with a diversity of architectures, demonstrated the deposition of electron-dense melanin granules (Fig. 3D). Melanotic Ma melanoma cells, which are native to the amelanotic $\mathrm{Ab}$ melanoma cells, cultured in the RPMI medium for $24 \mathrm{~h}$, were used as a positive control for melanosome presence (Fig. 4). They showed the presence of typical four stages of melanosomes: stage I (early endosomes), stage II (premelanosomes with patterned lamellar matrices), stage III (partially melanized melanosomes with lamellar patterns), stage IV (melanosomes in the final stage of melanization, showing uniformly melanin-filled electron-dense granular cores). In the Ma cells granular melanosomes dominated whereas fibrillar melanosomes were rare (Fig. 4C).

\section{Discussion}

Amelanotic melanoma is one of the less known forms of melanoma, and is characterized by a lack of melanin, lower cell differentiation, higher malignancy, and worse prognosis than melanotic melanomas [2, 9-11]. Melanization of amelanotic melanoma cells in vitro is very important aspect, especially as the melanoma lines most easily grown in vitro are amelanotic forms, and are used as targets for testing new chemotherapeutics. The process of in vitro amelanotic melanoma melanization has been known for many years but is not fully understood [24-28]. However, the modulation of melanin levels in melanoma cells is perhaps a means by which melanoma cells become sensitized to therapy [29-32].

Two media are generally used in culturing amelanotic melanoma cells: RPMI and DMEM. The differences in their effects on melanization have been checked in human melanoma SKMEL188 cells [28] and mouse B16F10 cells [25]. In SKMEL188 cells, DMEM enhanced melanin production, while strongly stimulating the expression of tyrosinase and melanocortin 1 receptor (MC1R) genes. Additionally, DMEM was found to stimulate tyrosinase activity five times more strongly than L-tyrosine alone [28]. B16F10 cells cultured in DMEM showed tyrosinase activity, produced melanin, and underwent morphological changes (in the form of developing dendrites), 


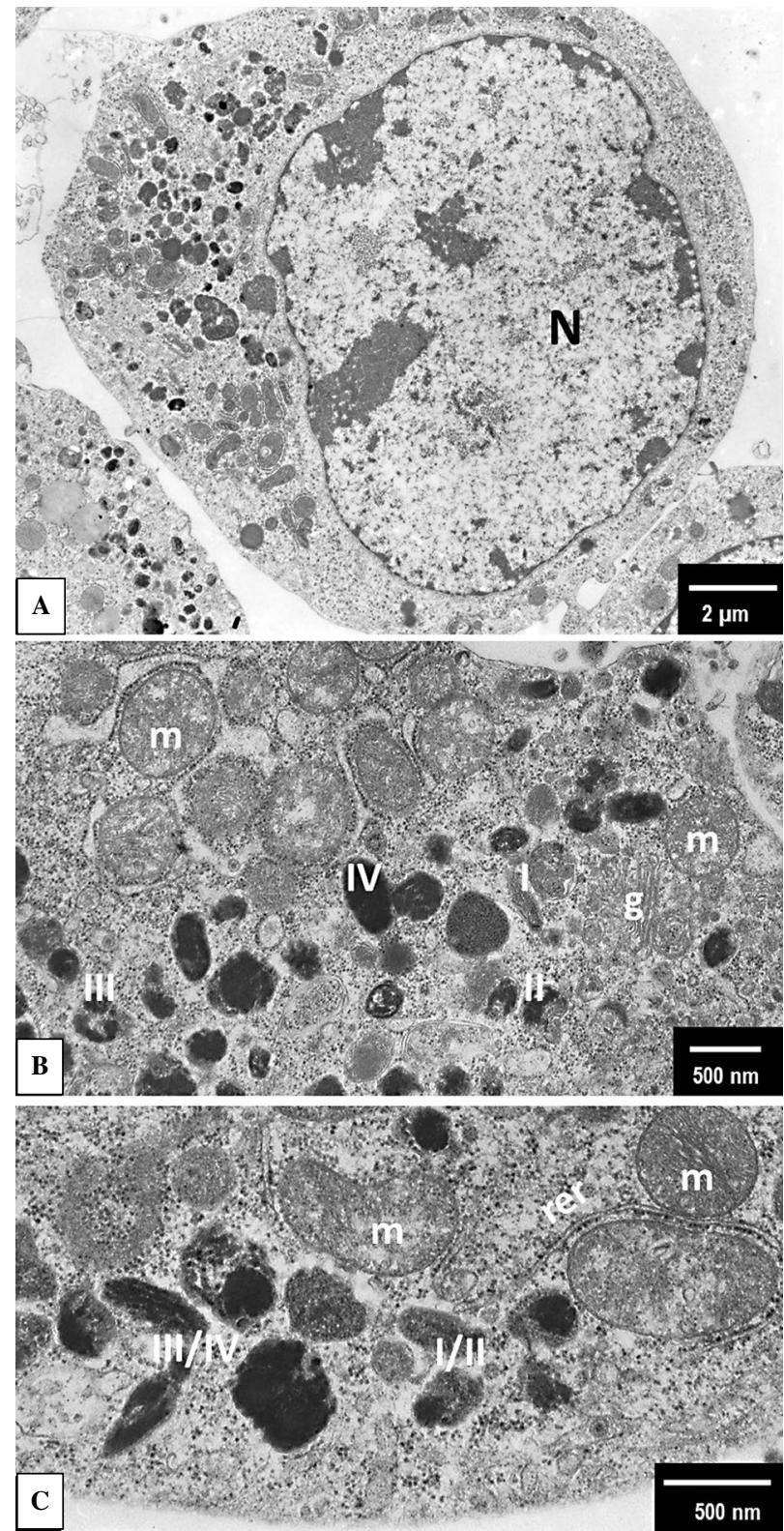

Figure 4. Ultrastructure of melanotic Ma melanoma cells cultured for $24 \mathrm{~h}$ in RPMI medium. A. General view of the Ma melanoma cell with melanosomes as electron-dense in a form of elongated to oval organelles. B and C. Melanosomes at four different stages of melanization. Stages: I. early endosomes; II. premelanosomes with patterned lamellar matrices; III. partially melanized melanosomes with lamellar patterns; IV. melanosomes in the final stage of melanization, showing uniformly melanin-filled electron-dense granular cores. Abbreviations: $\mathrm{N}$ - nucleus; $\mathrm{m}$ - mitochondria; $\mathrm{g}$ - Golgi apparatus; rer — rough endoplasmic reticulum.

but the elevated levels of tyrosine and phenylalanine in this medium were not the only factors responsible for phenotypic changes [25]. Additional factors that might enhance melanization include cAMP and $\alpha \mathrm{MSH}$ [25]. Our results on the hamster amelanotic
Ab line also confirm the observation that DMEM can induce melanogenesis in amelanotic melanoma cells. DMEM does not have the same effect on all human amelanotic melanoma lines - for example, it is the medium recommended by the American Type Culture Collection for the A375 melanoma line, which is widely used in many laboratories.

Over 30 years ago, hamster amelanotic $\mathrm{Ab}$ melanoma cells were cultured in vitro in Eagle's minimum essential medium, and from the third day begun melanin production, inhibiting proliferation $[20,21]$. Our results indicate that the contemporary use of DMEM for melanoma cells in vitro cultures also induces melanization of the Ab melanoma line. This result confirms that amelanotic melanoma cells transferred to an in vitro environment could follow the melanization, leading to the appearance of melanosomes, which were not present in the Ab melanoma tissue in vivo [21].

$\mathrm{Ab}$ melanoma cells cultured in RPMI also underwent very weak melanization, which can be explained by the presence of small amounts of tyrosinase in the medium and fetal bovine serum (FBS) - an ingredient of both media which, according to Słomiński et al., has a stimulatory effect on proliferation and melanization [33]. Apart from FBS, the L-tyrosine and L-DOPA (precursors of the melanogenic pathway) present in media could affect melanization [34].

In this experiment, we used two media that have significantly different levels of L-tyrosine: RPMI and DMEM. L-tyrosine stimulates melanosome synthesis and tyrosinase translocation to the melanosomes [35]. L-tyrosine hydroxylates into L-DOPA, which weakly stimulates the formation of premelanosomes $[34,36]$. It is worth recalling that a lack of premelanosomes is regarded as the main reason for melanogenesis inhibition in the amelanotic $\mathrm{Ab}$ line. The effect of higher levels of L-tyrosine in the medium seems to be confirmed in our experiment: Ab cells cultured in DMEM undergo faster melanization because DMEM contains more L-tyrosine than RPMI-1640. Melanin was heavily produced in parallel with darkening of the cell pellets. The stimulatory effect of DMEM on melanosomes formation is also documented by the ultrastructural analysis, which showed that melanosomes were present in Ab cells after 24 hours of incubation, despite having been absent at time 0 . During the progress of melanization, melanosomes were observed at different stages to contain melanin.

During culturing of the Ab melanoma cells in DMEM, the amount of tyrosinase protein increased, melanization did not always follow as a result of the increase in tyrosinase protein and tyrosinase activity [37]. According to Słomiński et al., higher level of ty- 
rosine, substrate for tyrosinase, protects the tyrosinase enzyme from degradation and enable it to accumulate in melanosomes [36].

The induction of melanization in amelanotic melanoma cells by a medium with higher level of L-tyrosine is an example of substrate influence on a metabolic pathway - in this case, melanogenesis - which can alter the biology of the target cells. L-tyrosine acts as a positive regulator of melanin synthesis, tyrosinase activity, and melanosome formation in a time-dependent manner. Thus, during the in vitro culturing of melanoma cells, it is very important to consider the content of tyrosine in the culture medium to avoid induction of melanogenesis. Melanogenesis is a functionally basic process for melanoma cells, and so any change may affect the biology of such tumor cells and their reaction to environmental factors, including drugs and radiotherapy.

\section{Acknowledgements}

This work was supported by statutory funds of the Medical University of Gdansk: MN 01-0138/08 (granted to A.S.) and ST 02-0075 (granted to M.C.)

\section{Conflict of interest}

The authors declare that they have no conflicts of interest.

\section{References}

1. Koch SE, Lange JR. Amelanotic melanoma: the great masquerader. J Am Acad Dermatol. 2000; 42 (5 Pt 1): 731-734, indexed in Pubmed: 10775846.

2. Thomas NE, Kricker A, Waxweiler WT, et al. Genes, Environment, and Melanoma (GEM) Study Group. Comparison of clinicopathologic features and survival of histopathologically amelanotic and pigmented melanomas: a population-based study. JAMA Dermatol. 2014; 150(12): 1306-1314, doi: 10.1001/jamadermatol.2014.1348, indexed in Pubmed: 25162299.

3. Giuliano AE, Cochran AJ, Morton DL. Melanoma from unknown primary site and amelanotic melanoma. Semin Oncol. 1982; 9(4): 442-447, indexed in Pubmed: 7170630.

4. Gualandri L, Betti R, Crosti C. Clinical features of 36 cases of amelanotic melanomas and considerations about the relationship between histologic subtypes and diagnostic delay. J Eur Acad Dermatol Venereol. 2009; 23(3): 283-287, doi: 10.1111/j.1468-3083.2008.03041.x, indexed in Pubmed: 19207640.

5. Kycler W, Grodecka-Gazdecka S, Bręborowicz J, et al. Prognostic value of selected immunohistochemical markers in skin melanoma. Nowotwory. 2002; 52: 487-495.

6. Perry MD, Seigler HF, Johnston WW. Diagnosis of metastatic malignant melanoma by fine needle aspiration biopsy: a clinical and pathologic correlation of 298 cases. J Natl Cancer Inst. 1986; 77(5): 1013-1021, indexed in Pubmed: 3464794.

7. Kapila K, Kharbanda K, Verma K. Cytomorphology of metastatic melanoma--use of S-100 protein in the diagnosis of amelanotic melanoma. Cytopathology. 1991; 2(5): 229-237, indexed in Pubmed: 1782361.

8. Cordoro KM, Gupta D, Frieden IJ, et al. Pediatric melanoma: results of a large cohort study and proposal for modified $\mathrm{ABCD}$ detection criteria for children. J Am Acad Dermatol. 2013; 68(6): 913-925, doi: 10.1016/j.jaad.2012.12.953, indexed in Pubmed: 23395590.

9. Cos S, Garcia-Bolado A, Sánchez-Barceló EJ. Direct antiproliferative effects of melatonin on two metastatic cell sublines of mouse melanoma (B16BL6 and PG19). Melanoma Res. 2001; 11(2): 197-201, indexed in Pubmed: 11333131.

10. Potti A, Moazzam N, Langness E, et al. Immunohistochemical determination of HER-2/neu, c-Kit (CD117), and vascular endothelial growth factor (VEGF) overexpression in malignant melanoma. J Cancer Res Clin Oncol. 2004; 130(2): 80-86, doi: 10.1007/s00432-003-0509-8, indexed in Pubmed: 14634801.

11. Vad NM, Yount G, Moridani MY. Biochemical mechanism of acetylsalicylic acid (Aspirin) selective toxicity toward melanoma cell lines. Melanoma Res. 2008; 18(6): 386-399, doi: 10.1097/CMR.0b013e3283107df7, indexed in Pubmed: 18971789.

12. Bomirski A, Słominski A, Bigda J. The natural history of a family of transplantable melanomas in hamsters. Cancer Metastasis Rev. 1988; 7(2): 95-118, indexed in Pubmed: 3293837.

13. Cichorek M. Spontaneous and induced apoptosis of two hamster transplantable melanoma lines differing in their biological features. Ann Acad Med Gedan. 2006; 36(Sup.7): 1-149.

14. Bomirski A. Biological properties of transplantable melanomas in the Syrian hamster during 16 years of maintenance by several passages. Habilitation thesis. Medical Academy of Gdansk. Gdansk, Poland 1977.

15. Cichorek M, Kozłowska K, Bryl E. Mitochondrial transmembrane potential in spontaneous and camptothecin-induced apoptosis of melanotic and amelanotic melanoma cells. Neoplasma. 2007; 54(1): 29-36, indexed in Pubmed: 17203890.

16. Cichorek M, Kozłowska K, Bryl E. The activity of caspases in spontaneous and camptothecin-induced death of melanotic and amelanotic melanoma cell. Cancer Biol Ther. 2007; 6(3): 346-353, indexed in Pubmed: 17312383.

17. Sidor-Kaczmarek J, Cichorek M, Spodnik JH, et al. Proteasome inhibitors against amelanotic melanoma. Cell Biol Toxicol. 2017; 33(6): 557-573, doi: 10.1007/s10565-017-9390-0, indexed in Pubmed: 28281027.

18. Dębowski D, Cichorek M, Lubos M, et al. Noncovalent inhibitors of human 20S and 26S proteasome based on trypsin inhibitor SFTI-1. Biopolymers. 2016; 106(5): 685-696, doi: 10.1002/bip.22886, indexed in Pubmed: 27258473.

19. Halaban R, Cheng E, Zhang Y, et al. Aberrant retention of tyrosinase in the endoplasmic reticulum mediates accelerated degradation of the enzyme and contributes to the dedifferentiated phenotype of amelanotic melanoma cells. Proc Natl Acad Sci U S A. 1997; 94(12): 6210-6215, indexed in Pubmed: 9177196.

20. Słomiński A. Some properties of Bomirski Ab amelanotic melanoma cells, which underwent spontaneous melanization in primary cell culture. Growth kinetics, cell morphology, melanin content and tumorigenicity. J Cancer Res Clin Oncol. 1985; 109(1): 29-37, indexed in Pubmed: 3972882.

21. Słomiński A, Słomiński A. Rapid melanization of Bomirski amelanotic melanoma cells in cell culture. Biosci Rep. 1983; 3(2): 189-194, indexed in Pubmed: 6189530.

22. Prota G. The Chemistry of Melanins and Melanogenesis. Fortschritte der Chemie organischer Naturstoffe / Progress in the Chemistry of Organic Natural Products. 1995: 93-148, doi: 10.1007/978-3-7091-9337-2 2. 
23. Siegrist W, Eberle AN. In situ melanin assay for MSH using mouse B16 melanoma cells in culture. Anal Biochem. 1986; 159(1): 191-197, indexed in Pubmed: 3812999.

24. Chen YM, Chavin W. Melanogenesis in human melanomas. Cancer Res. 1975; 35(3): 606-612, indexed in Pubmed: 803870.

25. Prezioso JA, Wang N, Duty L, et al. Enhancement of pulmonary metastasis formation and gamma-glutamyltranspeptidase activity in B16 melanoma induced by differentiation in vitro. Clin Exp Metastasis. 1993; 11(3): 263-274, indexed in Pubmed: 8097141.

26. Ancans J, Thody AJ. Activation of melanogenesis by vacuolar type $\mathrm{H}(+)$-ATPase inhibitors in amelanotic, tyrosinase positive human and mouse melanoma cells. FEBS Lett. 2000; 478(1-2): 57-60, indexed in Pubmed: 10922469.

27. Cohen-Solal KA, Crespo-Carbone SM, Namkoong J, et al. Progressive appearance of pigmentation in amelanotic melanoma lesions. Pigment Cell Res. 2002; 15(4): 282-289, indexed in Pubmed: 12100494.

28. Slominski A, Ermak G, Wortsman J. Modification of melanogenesis in cultured human melanoma cells. In Vitro Cell Dev Biol Anim. 1999; 35(10): 564-565, doi: 10.1007/s11626999-0093-6, indexed in Pubmed: 10614864.

29. Slominski A, Paus R, Mihm MC. Inhibition of melanogenesis as an adjuvant strategy in the treatment of melanotic melanomas: selective review and hypothesis. Anticancer Res. 1998; 18(5B): 3709-3715, indexed in Pubmed: 9854482.

30. Brozyna AA, VanMiddlesworth L, Slominski AT. Inhibition of melanogenesis as a radiation sensitizer for melanoma therapy. Int J Cancer. 2008; 123(6): 1448-1456, doi: 10.1002/ ijc.23664, indexed in Pubmed: 18567001.
31. Slominski A, Zbytek B, Slominski R. Inhibitors of melanogenesis increase toxicity of cyclophosphamide and lymphocytes against melanoma cells. Int J Cancer. 2009; 124(6): 1470-1477, doi: 10.1002/ijc.24005, indexed in Pubmed: 19085934

32. Wasiewicz T, Szyszka P, Cichorek M, et al. Antitumor effects of vitamin D analogs on hamster and mouse melanoma cell lines in relation to melanin pigmentation. Int J Mol Sci. 2015; 16(4): 6645-6667, doi: 10.3390/ijms16046645, indexed in Pubmed: 25811927.

33. Słomiński A, Bomirski A, Scisłowski PW, et al. Tyrosinase activity in primary cell culture of amelanotic melanoma cells. Biosci Rep. 1983; 3(11): 1027-1034, indexed in Pubmed: 6140964.

34. Słominski A, Moellmann G, Kuklinska E, et al. Positive regulation of melanin pigmentation by two key substrates of the melanogenic pathway, L-tyrosine and L-dopa. J Cell Sci. 1988; 89 ( Pt 3): 287-296, indexed in Pubmed: 3143738.

35. Slominski A, Costantino R. L-tyrosine induces tyrosinase expression via a posttranscriptional mechanism. Experientia. 1991; 47(7): 721-724, indexed in Pubmed: 1906010.

36. Slominski A, Costantino R. Molecular mechanism of tyrosinase regulation by L-dopa in hamster melanoma cells. Life Sci. 1991; 48(21): 2075-2079, indexed in Pubmed: 1903481.

37. Slominski A, Zmijewski MA, Pawelek J. L-tyrosine and L-dihydroxyphenylalanine as hormone-like regulators of melanocyte functions. Pigment Cell Melanoma Res. 2012; 25(1): 14-27, doi: 10.1111/j.1755-148X.2011.00898.x, indexed in Pubmed: 21834848.

Submitted: 23 March, 2018

Accepted after reviews: 5 October, 2018 Available as AoP: 29 October, 2018 